\title{
GLIAL FIBRILLARY ACIDIC PROTEIN-LIKE IMMUNOREACTIVITY IN THE IRIS: DEVELOPMEN'T, DISTRIBUTION, AND REACTIVE CHANGES FOLLOWING TRANSPLANTATION ${ }^{1}$
}

\author{
HÅKAN BJÖRKLUND,² DORIS DAHL, ${ }^{*}$ LARS OLSON, AND ÅKE SEIGER \\ Department of Histology, Karolinska Institutet, Stockholm, Sweden and ${ }^{*}$ Department of Neuropathology, Harvard Medical \\ School and Spinal Cord Injury Research Laboratory, West Roxbury, Veterans Administration Medical Center, \\ Boston, Massachusetts
}

Received June 20, 1983; Revised October 21, 1983; Accepted October 30, 1983

\begin{abstract}
Using immunohistochemistry with antisera raised against the glial fibrillary acidic protein (GFA), we have studied the appearance and distribution of GFA-like immunoreactivity in whole mounts of rodent iris and in sectioned cat and cow iris. In the adult rat iris, a dense plexus of GFA-positive fibers was seen in both the dilator plate and the sphincter. The fluorescent fibers formed large meandering bundles and a dense irregular network of thinner fibers. In the sphincter, mainly thinner fibers were seen. Thin fibers were also seen winding around blood vessels in the dilator plate. In adult mouse iris, the GFA-positive fibers had a quite different distribution with a few radially oriented fiber bundles superimposed on a more regular network of thinner fibers. Adult guinea pig irides showed still another pattern of GFA-positive fibers with a low number of bundles and thinner fibers forming a sparse irregular network. In thicker fiber bundles of all three rodent species, as well as at branching sites of the thinner fibers, negative or weakly fluorescent swellings surrounded by GFA-like immunoreactivity were present. These structures probably represent the cellular origin of the GFA-positive fibers. Thick, strongly fluorescent fiber bundles, as well as numerous thinner fibers, were seen in sections of cat and cow iris. Prenatally, fibers were visualized at embryonic day 18 in the rat. In these irides as well as in irides from 21-day-old embryos and 1day old pups, most fibers werc organized in a gradually increasing system of thin meandering fiber bundles that showed limited branching. At postnatal day 6, a more mature network of thinner fibers had developed between the now more numerous fiber bundles.

No obvious increase or decrease in the amount of GFA-positive fibers was seen in irides grafted to the anterior eye chamber of adult rat recipients examined 1 and 6 days after grafting. However, in these irides, as well as in the host irides, strongly fluorescent spider-like cells with short branching processes and a negative nucleus were seen. These cells were more numerous and more strongly fluorescent in grafted irides as compared to recipient irides and in the 6-day iris grafts as compared to the 2-day grafts.

In all probability, the GFA-positive fibers and cells forming a network in adult irides from different species and in embryonic and grafted rat irides represent Schwann cells and their processes. The cellular origin of the spider-like cells in the iris grafts is less clear.
\end{abstract}

Glial fibrillary acidic protein (GFA) is the major constituent of astrocytic intermediate filaments (Eng et al., 1971; Dahl and Bignami, 1973), and immunohistochemistry with antisera against GFA has been widely

\footnotetext{
${ }^{1}$ This work was supported by Swedish Medical Research Council Grants 14X-06555, 14X-03185, 25P-6326, and 14P-5867, Swedish National Science Research Council Grant U-FR, 1522-100, Magnus Bergvalls Stiftelse, Karolinska Institutets fonder, The "Expressen" Prenatal Research Foundation, and The Swedish Council for Planning
}

used to study astrocytic development and differentiation during both normal and experimental conditions (see Bignami et al., 1980; Eng and DeArmond, 1981). Until recently GFA has been considered to be selectively lo-

and Coordination of Research, A1-5/251. D. D. was supported by the Veterans Administration. We thank Ms. Lena Hultgren, Ms. Anna Hultgård, and Ms. Ingrid Strömberg for skillful technical assistance and Mrs. Kristina Seiger for typing.

${ }^{2}$ To whom correspondence should be addressed. 
calized in astrocytes and consequently confined to the CNS (Bignami et al., 1972; Bignami and Dahl, 1974, 1977). Whether this is true or whether GFA is also present in peripheral glial cells is currently a matter of debate (Dahl et al., 1982). Recently, several laboratories have reported the presence of GFA-like immunoreactivity in different types of peripheral glial cells including cells in the rat enteric nervous system (Jessen and Mirsky, 1980), in the rat olfactory nerves (Barber and Lindsay, 1982), and a subpopulation of Schwann cells in rat sciatic nerve (Yen and Fields, 1981). These findings have recently been further supported by the immunochemical identification of a 50,000-dalton protein with GFA-immunoreactive properties in rat sciatic nerve as well as bovine splenic nerve (Yen and Fields, 1983). Furthermore, Yen and Fields (1981) showed that the amount of GFA-like immunoreactivity increased in sciatic nerves undergoing Wallerian degeneration, further supporting the glial origin of the immunoreactive structures.

The immunohistological findings of Yen and Fields (1981) were confirmed by Dahl et al. (1982). However, the latter investigators were unable to detect an antigen reacting with the GFA antisera in extracts of normal or degenerated rat sciatic nerve using several immunochemical techniques. We decided to study the possible presence of GFA-like immunoreactivity in stretch-prepared whole mounts of rodent iris and in cryostat-sectioned cat and cow iris. Whole mounts of irides have been widely used to study distribution, growth, and degeneration dynamics of sympathetic, parasympathetic, and sensory nerve fibers (Hillarp, 1946; Falck, 1962; Ehinger and Falck, 1966; Olson and Malmfors, 1970; Saari and Johansson, 1974; Miller et al., 1981). The advantage with whole mounted irides as compared to sectioned is that the normal more or less two-dimensional plexus of nerves and surrounding glial cells is preserved. Recently, the presence of neurofilament immunoreactive nerves in rodent, cat, and cow iris has been demonstrated (Seiger et al., 1984). Furthermore, by transplantation to the anterior eye chamber of adult recipients, it is possible to denervate the iris graft totally and then to study the reaction of the non-neuronal elements within it.

\section{Materials and Methods}

Animals. Twelve iris whole mounts were made using normal adult albino rats of both sexes (Sprague-Dawley) as donors. Short-term intraocular grafting of iris was performed as described earlier (Olson and Malmfors, 1970) using six similar animals as donors and an equal number of animals as recipients. In addition, four iris whole mounts from each of the four age groups, embryonic days 18 and 21 and postnatal days 1 and 6 , were made. Iris whole mounts were also made from six adult male albino mice (NMRI, $25 \mathrm{gm}$ ) and from four adult albino guinea pigs. All rodents were deeply ether anesthetized and killed by bleeding out or cervical dislocation (fetal material from pregnant rats). Irides were obtained from an adult $(4 \mathrm{~kg})$ female cat. The cat was anesthesized using Nembutal $(40 \mathrm{mg} / \mathrm{kg}$, i.p.). Two cow eyes were obtained from a slaughter house.

Immunofluorescence techniques. Rodent irides were stretch prepared as whole mounts (Falck, 1962; Malm- fors, 1965), on ethanol-washed, gelatin-coated slides and air dried from 1 to several hours. Cat and cow irides were tangentially sectioned at 10 to $14 \mu \mathrm{m}$ on a cryostat. The sections were fixed for $3 \mathrm{~min}$ in $100 \%$ acetone at room temperature. Antiserum to GFA was raised in rabbits against degraded antigen $\left(M_{\mathrm{r}}=40,500\right)$ isolated from phosphate buffer extracts of autolysed human spinal cord (Dahl and Bignami, 1976) and used diluted 1:100 in 0.1 M phosphate-buffered saline. Absorbed antiserum was used as a control. Slides were processed according to the indirect immunofluorescence technique (Coons, 1958). After a 10-min rinse in $0.1 \mathrm{M}$ phosphate buffer, the whole mounts were incubated with the GFA antiserum at $4^{\circ} \mathrm{C}$ overnight in a humid atmosphere. After rinsing in phosphate buffer for $3 \times 10 \mathrm{~min}$, the slides were incubated in either fluorescein isothiocyanate (FITC)-conjugated or rhodamin-conjugated sheep antirabbit antibodies (Dakopatts, Denmark) diluted 1:100 (FITC) or 1:50 (rhoda$\mathrm{min}$ ) for $1 \mathrm{hr}$ at room temperature in darkness. All antisera contained $0.3 \%(\mathrm{v} / \mathrm{v})$ Triton X-100. After a second rinse $(3 \times 10 \mathrm{~min})$, the slides were mounted in glycerine-phosphate buffer and examined in a darkfield fluorescence microscope. Tri-X film (Kodak) was used for photography.

\section{Results}

GFA in adult rat iris. A large number of strongly fluorescent smooth GFA-positive fibers against an almost negative background could be seen evenly distributed throughout the iris in both the dilator plate and the sphincter (Figs. 1 and 2). The fluorescent fibers formed a system of thicker bundles in the dilator, each large bundle consisting of approximately 10 to 20 fibers. Associated with these bundles thin fibers were seen forming a fine-meshed network. The network was slightly denser in the sphincter area than in the dilator, and the fibers could frequently be seen reaching the sphincter margin (Fig. $1 b$ ). Very few fiber bundles were found in the sphincter. Fluorescent structures ranged in diameter from less than 1 to several microns. A system of very thin and delicate fibers was seen winding around the blood vessels with a distribution reminiscent of the sympathetic noradrenergic innervation of these vessels (Fig. $2 b$ ). Cell body-like structures, including nonfluorescent nuclei, were frequently seen both in the fiber bundles and at the branching sites of thinner fibers (Fig. 1a). When absorbed antiserum was used as a control, the preparations were completely negative (Fig. 1c).

GFA in adult mouse iris. Compared with the rat the GFA-positive fibers in the mouse had a more regular organization with a background fluorescence that was even lower than in the rat irides (Fig. 3, $a$ and $b$ ). A few thick fiber bundles with an almost radial orientation were superimposed on a more sparse network of thinner, smooth fibers. The GFA-positive plexus in the mouse iris had an organization closely resembling the distribution of autonomic nerve fibers. Cell body-like areas (i.e., negative swellings surrounded by GFA-like immunoreactivity) were clearly seen both in fiber bundles and at junctions between thinner fibers (Fig. 3, $a$ and $b$, arrows).

GFA in adult guinea pig iris. In the dilator a quite sparse irregular plexus of thin, smooth fibers was seen 

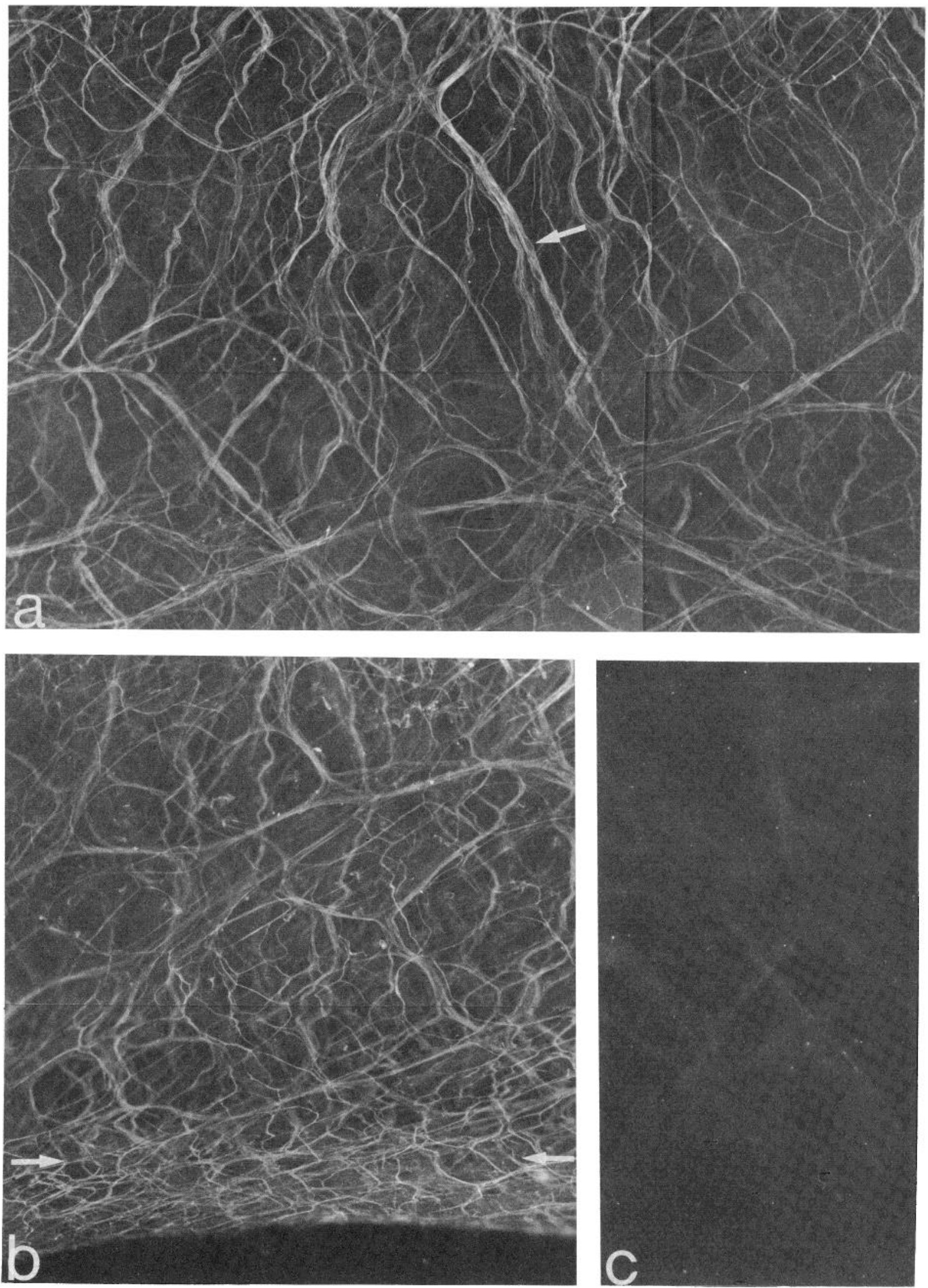

Figure 1. Distribution of GFA-positive fibers in adult stretch-prepared rat iris. Fluorescence microphotographs. Magnification $\times 135$. $a$, Fiber bundles consisting of 5 to 10 fibers are seen meandering over the dilator. A dense network of thin smooth fibers is present between the bundles. Note the small negative, nucleus-like areas surrounded by GFA-positive structures seen within the bundles (arrow). b, Sphincter area and nearby dilator plate. Almost only thin fibers are seen in the sphincter area, where they form a dense network frequently also reaching the edge of the sphincter. Arrows denote the border between dilator and sphincter. $c$, Stretch-prepared iris incubated with GFA antiserum absorbed with its proper antigen. No positive fluorescence is seen. 

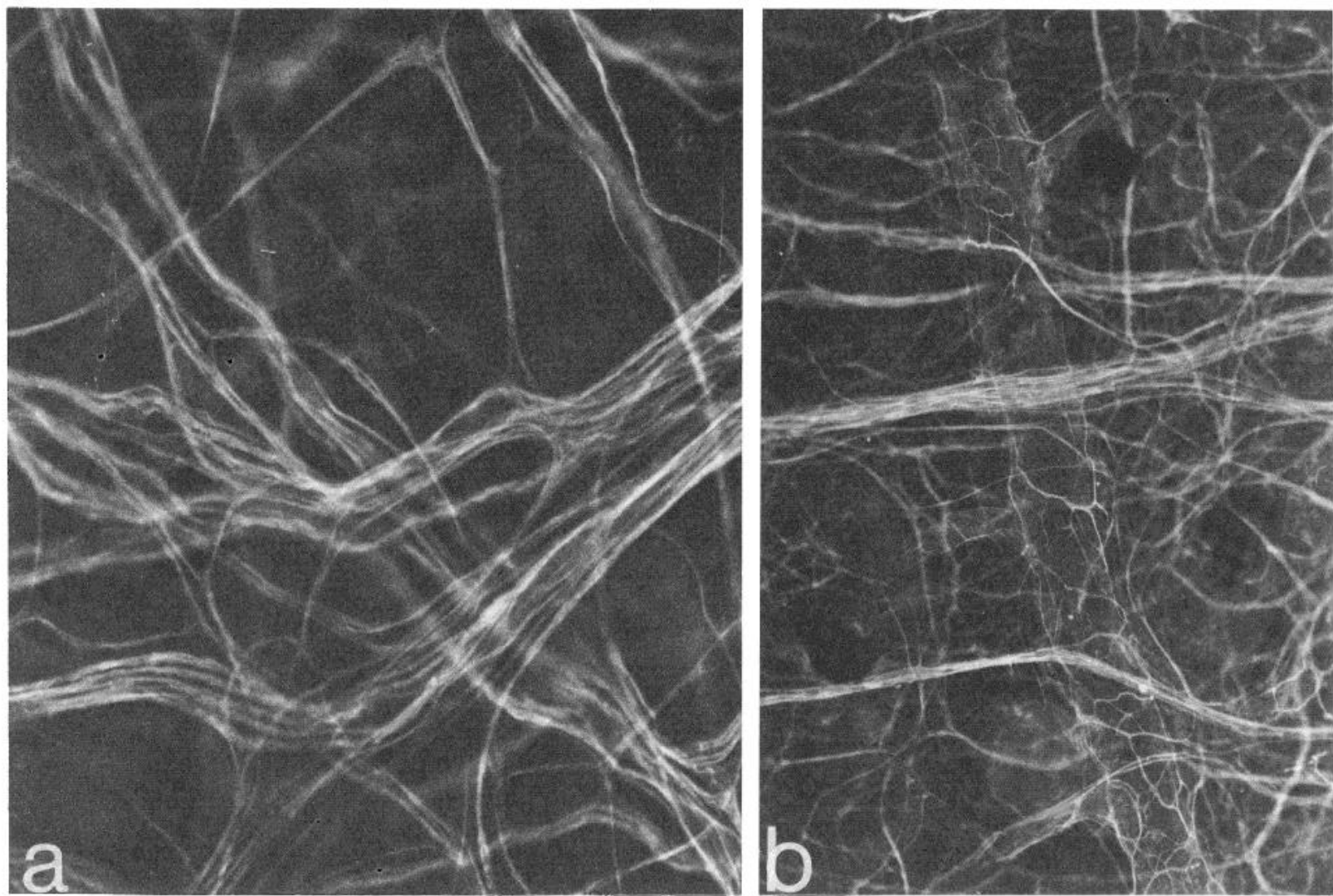

Figure 2. GFA-like immunoreactivity in stretch preparations of adult rat iris. Fluorescence microphotographs; $a, \times 195, b, \times$ 135. $a$, Close-up of the dilator area. Several bundles with fibers of varying thickness are seen. $b$, A large blood vessel with thin GFA-positive fibers is seen traversing the dilator.

against a background of numerous unspecifically fluorescent cell bodies, probably representing the epithelial cells on the posterior surface of the iris (Fig. $3 c$ ). Only a few fiber bundles were seen. In the sphincter a limited number of thinner fibers were visualized. However, it should be noted that the guinea pig iris is comparatively thick and not ideal for stretch preparations. Therefore, it is quite possible that not all GFA-positive fibers are seen and that the plexus is consequently more dense than is suggested from the whole mounts.

GFA in adult cat and cow iris. A dense system of GFApositive fibers was seen in sections of adult cat iris (Fig. $3 d)$. Thick, radially oriented fiber bundles were present both in the dilator and in the sphincter. Intermingled was a high number of strongly fluorescent smooth fibers that mainly had a radial orientation. In the bundles, the GFA-positive fibers seemed to surround thick myelinated axons. This was especially clearly seen in the ciliary processes where blood vessels also seemed to be encompassed by GFA-positive structures. In the cow iris, GFApositive bundles were even more prominent than in the cat iris. Such bundles and thin GFA-positive fibers were found throughout the iris tissue (Fig. 4).

Ontogeny of GFA-positive fibers in the rat iris. The earliest embryonic age at which the iris could be stretch prepared as a whole mount was day 18 of gestation. At this stage, a fine sparse strongly fluorescent plexus consisting mainly of fine fiber bundles was seen (Fig. $5 a$ ). At day 21 of gestation, the fiber bundles were more numerous and seemed to contain more fibers (Fig. $5 b$ ). Still, only a few thin fibers were seen.

In irides from 1-day-old rat pups, most of the fibers were still organized in bundles (Fig. $5 c$ ). In these irides, it was possible to identify the sphincter area and the ciliary body. It was then obvious that the fiber bundles were more extensively branching in the parts of the irides close to the sphincter, whereas in proximity to the ciliary processes fewer but thicker, mainly radially oriented, bundles were present. From postnatal day 6 , the GFAfluorescent structures were organized in a manner clearly resembling the adult organization. Fiber bundles were more numerous, showing both radial and circumferential meandering patterns (Fig. $5 d$ ). Although the thin fibers were much more numerous than at earlier developmental stages, especially in the sphincter, the fiber density was still clearly lower than in the adult iris.

GFA in iris grafts and host irides. GFA-positive fiber bundles, as well as thinner structures, were seen in whole mounts of iris grafts after 2 days in oculo (Fig. 6a). Grafted irides, and to a lesser extent the host irides, became swollen and more difficult to stretch prepare. This problem made it difficult to determine whether the density of GFA-positive fibers was unchanged or whether a slight increase or decrease had occurred in the irides. Numerous strongly fluorescent spider-like cells were also found (Fig. 6, $a$ and $b$ ). These cells were evenly distributed throughout the iris and usually had 5 to 10 short branching processes. The fluorescence had a grainy ap- 

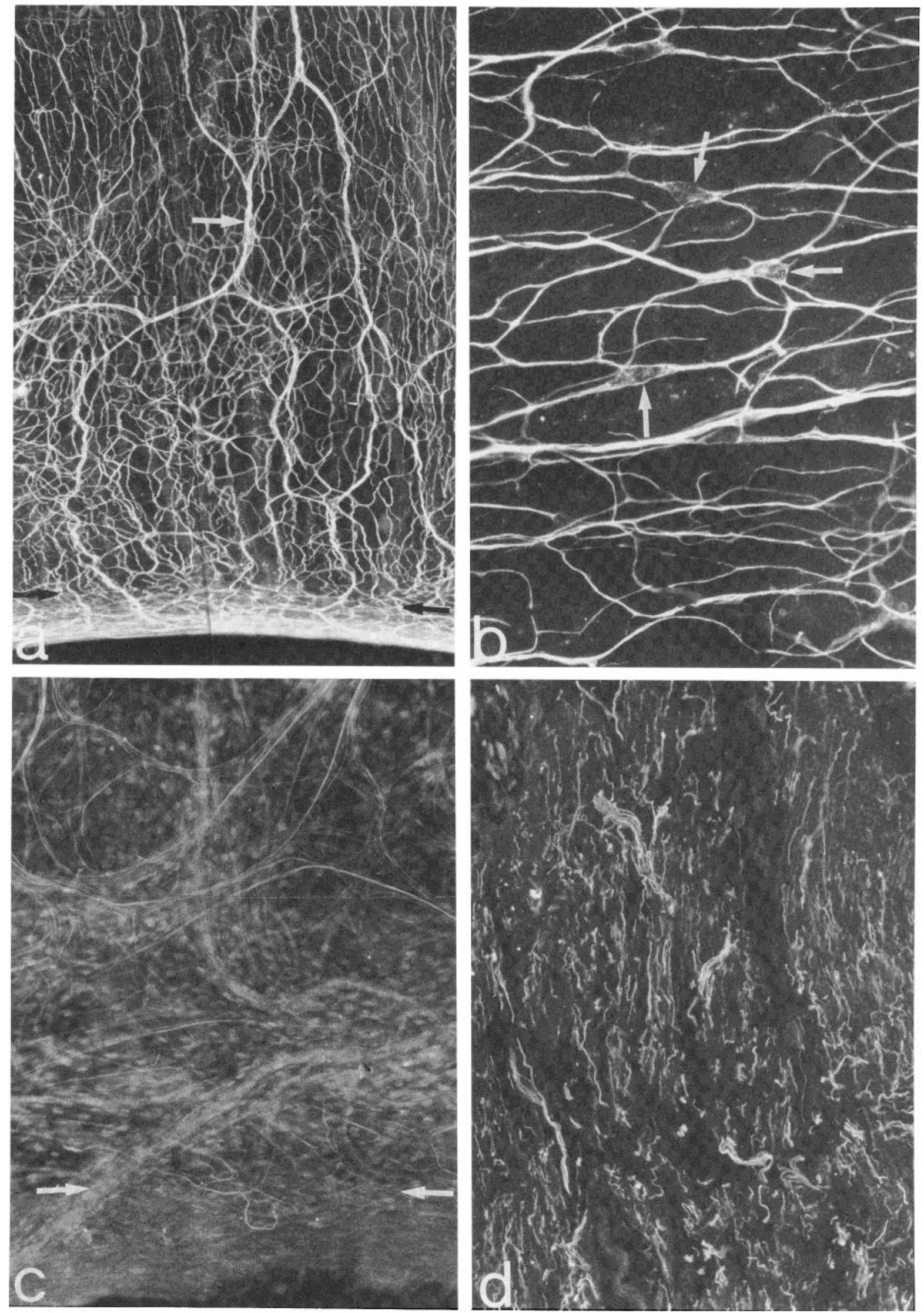

Figure 3. a, GFA-positive fibers in adult mouse iris. The bundles show a radial orientation, whereas the thinner fibers form a well organized network against a negative background. Fibers are also seen in the sphincter. Cell body-like structures are frequently seen (white arrow). Black arrows denote the border between dilator and sphincter. $b$, Close-up of dilator area as in $a$ to show the location of the cell bodies at junctional points in the plexus (arrows). $c$, GFA-positive fibers in adult guinea pig iris. A sparse irregular plexus, mainly consisting of fiber bundles, is seen in the dilator. In the sphincter a few fibers are seen. $d$, Tangential section through dilator plate of adult cat iris, revealing a rich system of GFA-positive fibers and thicker bundles. Fluorescence microphotographs; $a, c$, and $d, \times 135 ; b, \times 330$. 


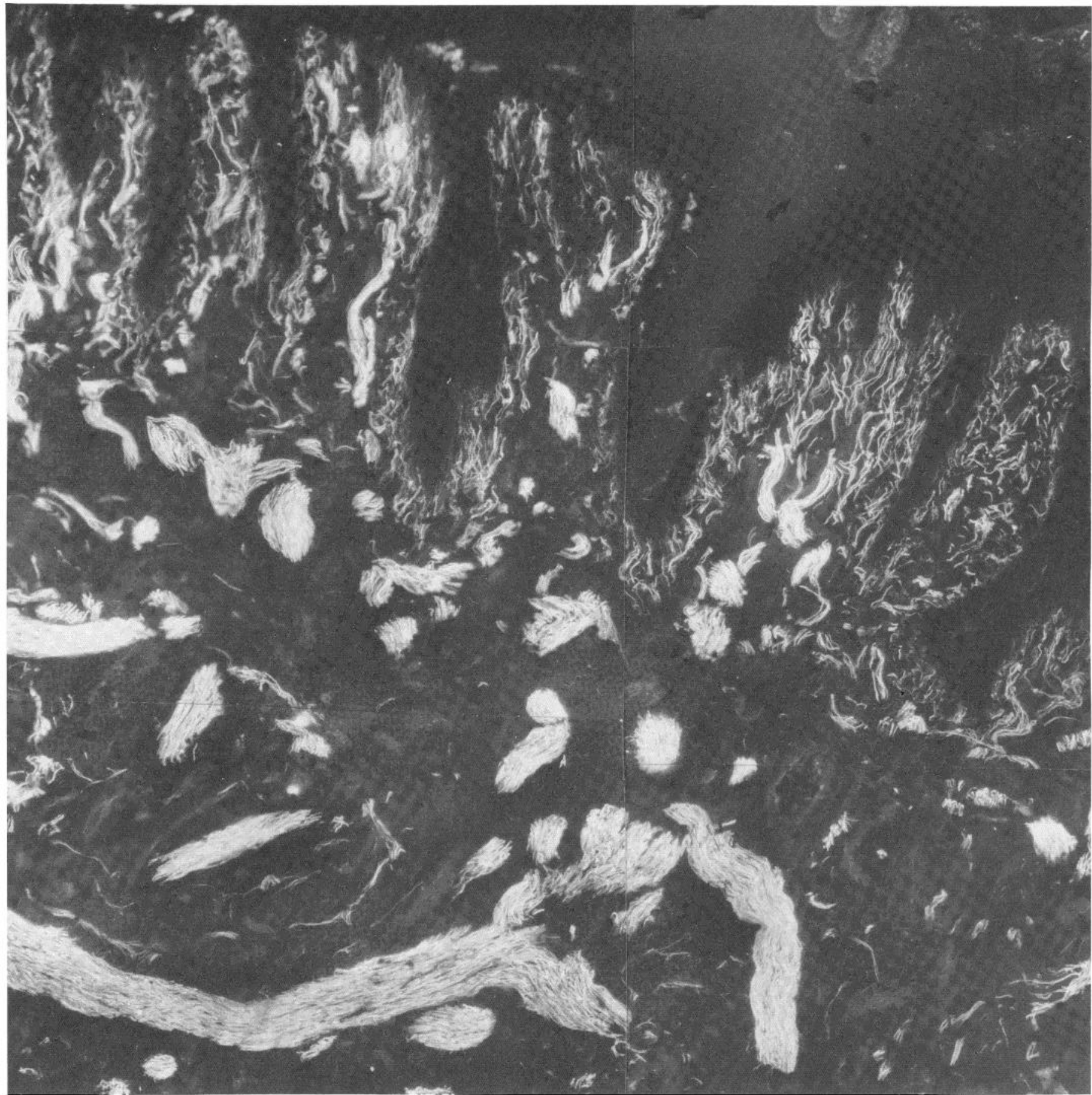

Figure 4. GFA-positive thick bundles and thinner fibers in tangentially sectioned cow iris. Fluorescence microphotographs. Magnification $\times 100$.

pearance and was continuous throughout the cells, sparing only the totally negative nucleus. It was difficult to see clearly whether these cells were connected to the normal fiber plexus, although most processes seemed to end abruptly. The same type of cells, although less numerous and more weakly fluorescent, was seen also in host irides (Fig. 6, $c$ and $d$ ). In iris grafts after 6 days in oculo, the GFA-positive fiber plexus looked quite dense, although the fiber bundles were more difficult to detect and the normal organization seemed slightly disrupted. Again, however, the thickness of the iris and, conse- quently, the increased background fluorescence made quantitative evaluations difficult. Fluorescent cells were more numerous and clearly more intensively fluorescent after 6 days in oculo (Fig. 6, $e$ and $f$ ). Similar but fewer and more weakly fluorescent cells were again seen in the host irides.

\section{Discussion}

This paper demonstrates the presence of GFA-like immunoreactivity in rodent, cat, and cow iris using a rabbit antiserum that does not cross-react with any of 

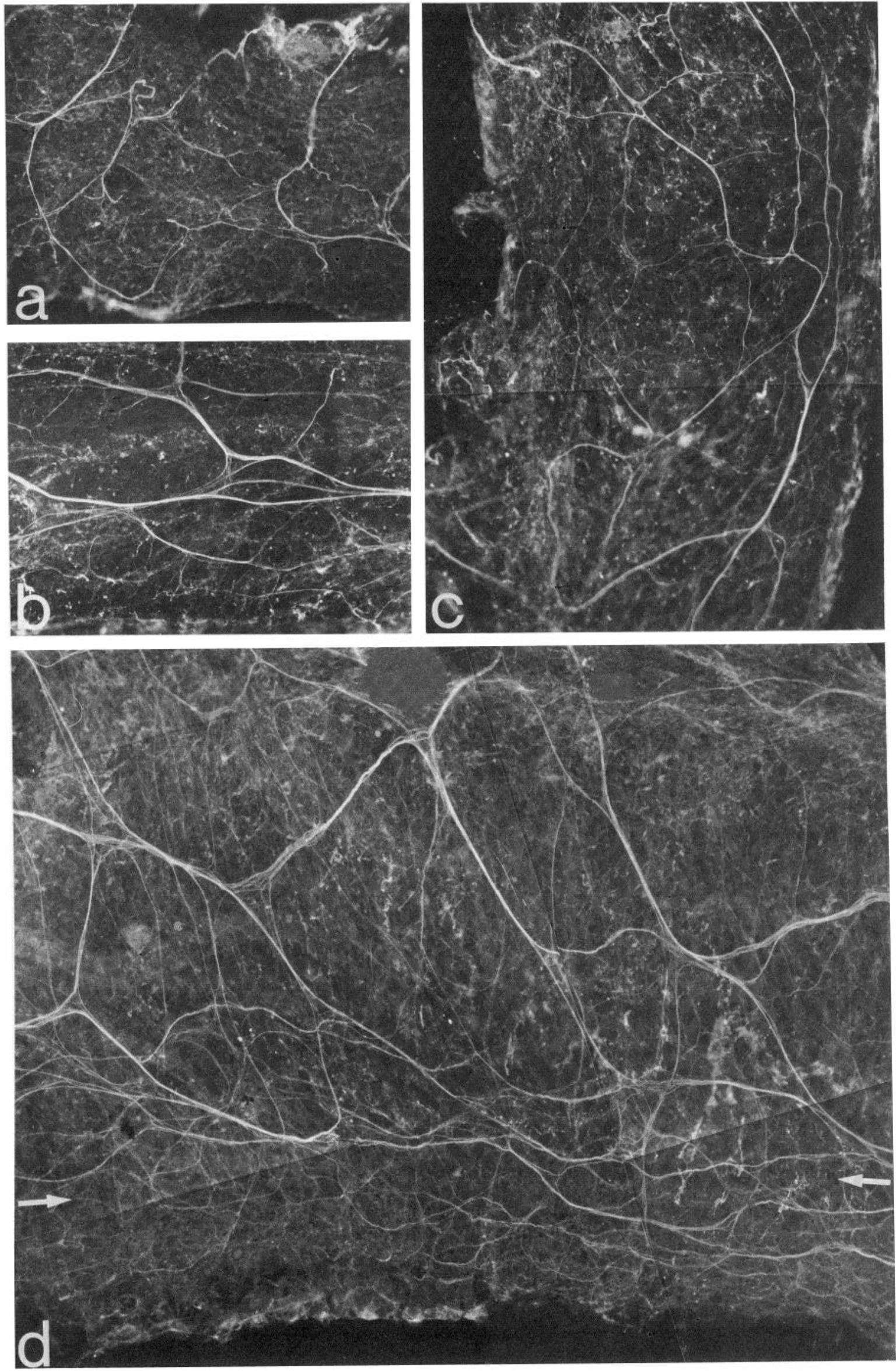

Figure 5 
the subunits of the neurofilament triplet (Raju et al., 1981). Thick fluorescent bundles associated with a plexus of thinner fibers were seen. Although this general fiber organization was apparent in all three rodent species, the total number of visible GFA-positive fibers in guinea pig iris was considerably lower than in mouse and rat. The reason for this difference could be technical, because the guinea pig iris is not ideal for stretch preparations due to its thickness. It is also possible that the GFA antiserum has a lower cross-reactivity with guinea pig than with other rodent species. Since the cat and cow irides were sectioned, it is difficult to compare the distribution and amount of GFA-positive fibers in these irides with the different rodent species. The distribution of neurofilament (NF)-reactive fibers in the same types of irides has recently been described (Seiger et al., 1984). The overall patterns of GFA and NF are similar, although it appears as if the glial intermediate filaments are contained in a larger proportion of the innervation network. Thus, a fine GFA-immunoreactive network is seen in the periarterial plexuses, where NF is not found.

Several different lines of evidence suggest that the GFA-positive fibers are peripheral glial fibers. They have a distribution that partly resembles that of nerve fibers in the iris, suggesting that the nerve fibers might be at least partly outlined by the GFA-positive fibers. If so, whether only certain types of nerves, such as sympathetic, parasympathetic, or sensory fibers, or only nerve fibers with a certain diameter are encompassed by GFApositive fibers is not clear. In the rat and mouse iris, the GFA-positive fibers form such a dense network that it is possible that most nerve fibers are outlined. In the mouse iris the distribution of GFA-positive fibers is actually closely resembling the adrenergic ground plexus (Malmfors, 1965). That the GFA-positive structures could be nerve fibers is ruled out by the fact that they do not disappear or show any other signs of degeneration in intraocular iris grafts. This shows that at least the large majority of the fibers are intrinsic to the iris. Weakly fluorescent cell body-like areas were clearly seen, especially in mouse iris, further supporting an intrinsic origin of the GFA-positive fibers. Similarly, the presence of such cell body-like structures surrounded by GFA-positive fibers was recently reported in sections of rat sciatic nerve processed for GFA immunohistochemistry (Dahl et al., 1982).

At day 18 of gestation, GFA-positive fibers were present in the iris, although in a very sparse plexus. However, in neonatal rat sciatic nerve, no Schwann cells are GFA positive, although a population of such cells is strongly fluorescent in the adult state (Yen and Fields, 1981). If a similar situation exists in the iris, it is possible that not all of the glial network is visualized. Also NF-like immunoreactivity can be seen at this developmental age organized in a quite similar, although slightly denser, network (Seiger et al., 1984). Further studies are needed to elucidate the temporal relationship between the appearance of GFA-like immunoreactivity and innervation of the iris.

The spider-formed GFA-positive cells that were visualized in both iris grafts and host iris are intriguing. We find it difficult to determine whether these cells are connected to the normal plexus of GFA-positive fibers. Their localization, often secmingly in the meshes of the network, suggests that they are at least not totally corresponding to the cell body-like structures seen in normal irides. Interestingly, an increased amount of GFA-like immunoreactivity in sciatic nerve undergoing Wallerian degeneration has been reported (Yen and Fields, 1981; Dahl et al., 1982). It is obviously important to clarify the relationship between (1) Schwann cells, (2) GFA-positive cells in normal irides, and (3) GFA-positive cells in disturbed (grafted and host) irides. Judging from the abundance of GFA-positive cells, e.g., in normal mouse irides, it seems plausible that these cells are at least part of the Schwann cell population. The cells found in disturbed irides may be derived from the same cell population having undergone morphological and/or biochemical reactive changes. Similar reactions may be expected following other disturbances of the intraocular homeostasis.

One interesting question raised by the demonstration of fibers and cells with GFA-like immunoreactivity in the iris is, of course, whether this immunoreactivity is due to the presence of a protein identical to CNS GFA. It is considered a unique characteristic of intermediate filaments that filaments of different cell types are immunologically distinct (see Lazarides, 1980). GFA is a major constituent of astrocyte intermediate filaments (Bignami et al., 1972; Dahl and Bignami, 1976), whereas vimentin was recently suggested to be the major component of Schwann cell filament preparations isolated from rabbit sciatic nerve 5 weeks after transection (Autilio-Gambetti et al., 1982). It has also been shown that astrocytes, apart from GFA-intermediate filament, contain high levels of vimentin during development using both immunohistochemistry and immunochemical procedures, whereas only low amounts are normally present in the adult state (Dahl, 1981; Dahl et al., 1981; H. Björklund, M. Eriksdotter-Nilsson, D. Dahl, and L. Olson, submitted for publication). Similarly, the presence of GFA-like immunoreactivity has been reported in glial cells in the enteric plexus of the rat (Jessen and Mirsky, 1980) and in some Schwann cells in rat sciatic nerve using GFA antisera raised in five different laboratories (Yen and Fields, 1981). These latter authors showed that GFA-like immunoreactivity could be abolished if the

Figure 5. Pre- and postnatal development of GFA-positive fibers in rat iris. Fluorescence microphotographs. Magnification $\times$ 135. a, Embryonic day 18. A few thin fiber bundles and a limited number of thin fibers are present. $b$, Embryonic day 21 ; and $c$, postnatal day 1. The same general pattern as in $a$, although the bundles are slightly thicker and the thin fiber network is more extensive. $d$, Postnatal day 6 . The plexus of GFA-positive fibers has a more mature appearance with a high number of thin fibers between the bundles, especially near the sphincter. The fiber bundles have a radial orientation in the parts of the dilator near the ciliary processes (upper part), whereas they have a circumferential pattern close to the sphincter (lower part). Arrows denote the border between dilator and sphincter. 

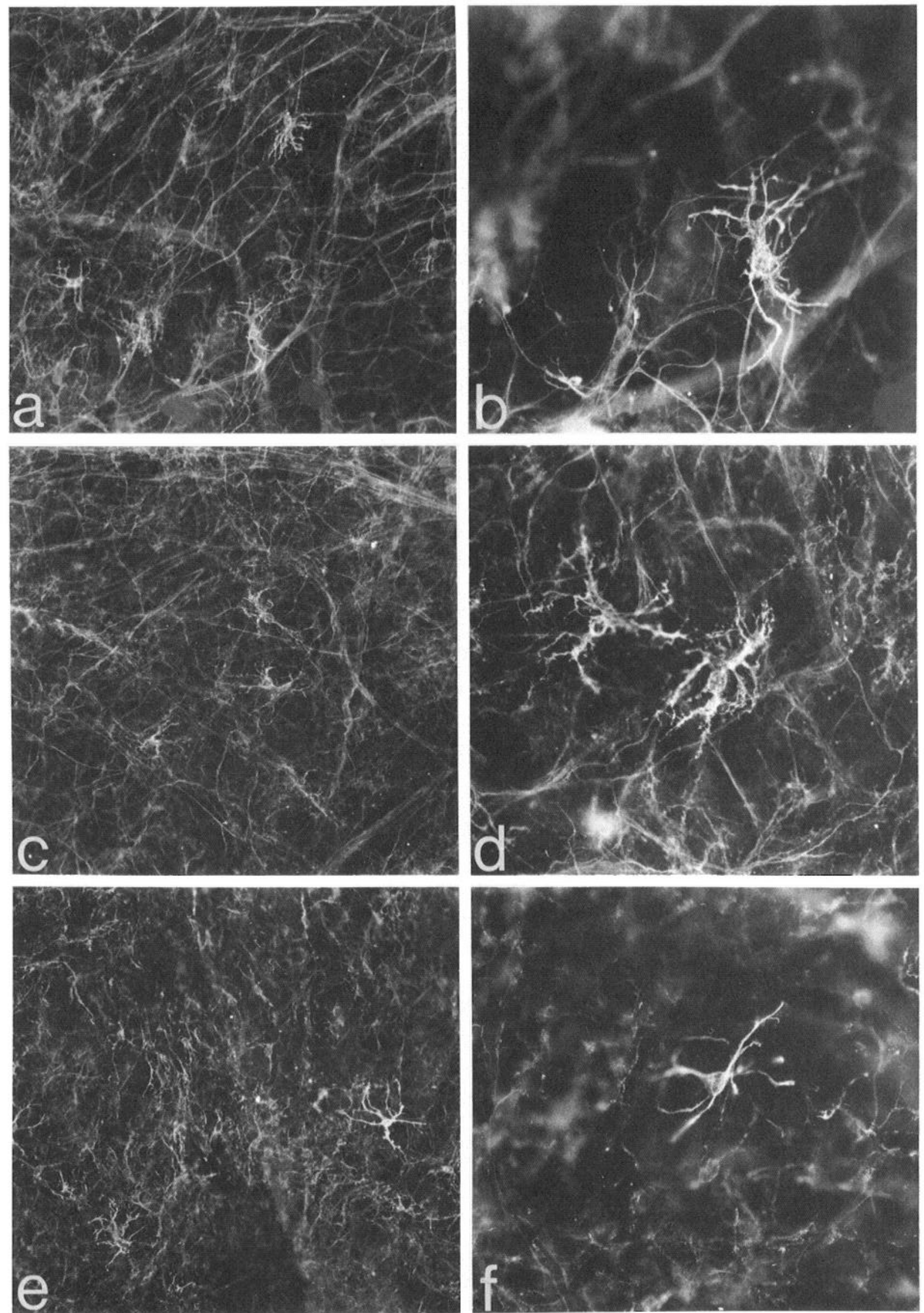

Figure 6. GFA-positive fibers and cells in stretch-prepared intraocular iris grafts and recipient irides. Fluorescence microphotographs; $a, c$, and $e, \times 135 ; b, d$, and $f, \times 330$. $a$ and $b$, Iris grafts stretch prepared after 2 days in oculo. A seemingly normal fiber plexus with bundles and thin fibers is seen. Strongly fluorescent spider-like cells with positive cell bodies and processes are seen. $c$ and $d$, Stretch preparations of host irides 2 days after grafting. The same type of cells as in $a$ and $b$ are seen, although they are less numerous and their fluorescence intensity is lower. $e$ and $f$, Iris grafts stretch prepared after 6 days in oculo. A dense but somewhat irregular plexus of GFA-positive fibers is seen intermingled with brightly fluorescent cells. 
antisera were adsorbed by brain filament preparations or with Triton-insoluble cytoskeletal proteins from cultured astrocytes but not with cytoskeletal proteins from cultured fibroblasts. Also, recent observations from the same laboratory indicate the presence of immunochemically identified GFA protein in peripheral nerves (Yen and Fields, 1983). Dahl et al. (1982) confirmed the presence of GFA-like immunoreactivity in rat sciatic nerve but were unable to demonstrate the presence of an antigen reacting with GFA antisera in extracts from both normal and degenerated sciatic nerves using several immunochemical procedures capable of detecting GFA protein in brain and spinal cord extracts. A possible reason for this discrepancy in the immunochemical analysis compared to Yen and Fields (1983) could be minor differences between the different GFA antisera utilized.

Using immunoelectrophoresis, we have seen a high concentration of S-100, an acidic protein first isolated from the brain (Moore, 1965; Moore and McGregor, 1965 ), where it is mainly localized in astrocytes (Haglid et al., 1974, 1975; Björklund, et al., 1983), in the rat iris, whereas submandibular glands did not contain any detectable S-100 protein $(\mathrm{H}$. Björklund, K. Haglid, L. Rosengren, and L. Olson, unpublished data), further supporting a relation between astrocytes and glial cells in the iris. Similarly, S-100-like immunoreactivity has been demonstrated in glial cells in the human enteric nervous system (Ferri et al., 1982). The possibility exists that our GFA antiserum cross-reacts with another intermediate filament protein that has common antigenic determinants with GFA. This possibility is supported by the production of a monoclonal antibody that reacts with all classes of intermediate filaments using immunohistochemistry (Pruss et al., 1981). Similarly, Gown and Vogel (1982) produced monoclonal antibodies reacting with several different types of intermediate filaments. Thus, it is now clear that, although different intermediate filaments are distinct proteins, they do share some common antigenic determinants. However, using a GFA antiserum, shown by immunoblotting not to cross-react with vimentin, the same fiber plexus is visualized as with the normal GFA-antiserum.

We conclude that immunofluorescence with GFA antiserum can be used to visualize a rich plexus of fibers and cells in rodent, cat, and cow irides in all probability representing Schwann cells or a subgroup of the Schwann cells and their processes. Reactive changes, including cells with a different morphology, occur in disturbed irides.

\section{References}

Autilio-Gambetti, L., J. Sipple, O. Sudilovsky, and P. Gambetti (1982) Intermediate filaments in Schwann cell. J. Neurochem. 38: 774-780.

Barber, P. C., and R. M. Lindsay (1982) Schwann cells of the olfactory nerves contain glial fibrillary acidic protein and resemble astrocytes. Neuroscience 7: 3077-3090.

Bignami, A., and D. Dahl (1974) Astrocyte specific protein and neuroglial differentiation. An immunofluorescence study with antibodies to the glial fibrillary protein. J. Comp. Neurol. 153: 27-38.

Bignami, A., and D. Dahl (1977) Specificity of the glial fibrillary acidic protein for astroglia. J. Histochem. Cytochem. 25:466469.

Bignami, A., L. F. Eng, D. Dahl, and C. T. Uyeda (1972) Localization of the glial fibrillary acidic protein in astrocytes by immunofluorescence. Brain Res. 43: 429-435.

Bignami, A., D. Dahl, and C. Rueger (1980) Glial fibrillary acidic (GFA) protein in normal neural cells and in pathological conditions. In Advances in Cellular Neurobiology, $\mathrm{S}$. Fedoroff and I. Hertz, eds., Vol. 1, pp. 285-319, Academic Press, Inc., New York.

Björklund, H., D. Dahl, K. Haglid, L. Rosengren, and L. Olson (1983) Astrocytic development in fetal parietal cortex grafted to cerebral and cerebellar cortex of immature rats. Dev. Brain Res. 9: 171-180.

Coons, A. H. (1958) Fluorescent antibody methods. In General Cytochemical Methods, J. F. Danielli, ed., pp. 399-422, Academic Press, New York.

Dahl, D. (1981) The vimentin-GFA protein transition in rat neuroglia cytoskeleton occurs at the time of myelination. J. Neurosci. Res. 6: 741-748.

Dahl, D., and A. Bignami (1973) Glial fibrillary acidic protein from normal human brain. Purification and properties. Brain Res. 57: 343-360.

Dahl, D., and A. Bignami (1976) Immunogenic properties of the glial fibrillary acidic protein. Brain Res. 116: 150-157.

Dahl, D., D. C. Rueger, A. Bignami, K. Weber, and M. Osborn (1981) Vimentin, the 57,000 molecular weight protein of fibroblast filaments, is the major cytoskeletal component in immature glia. Eur. J. Cell Biol. 24: 191-196.

Dahl, D., N. H. Chi, L. E. Miles, B. T. Nguyen, and A. Bignami (1982) Glial fibrillary acidic (GFA) protein in Schwann cells: Fact or artifact. J. Histochem. Cytochem. 30: 912-918.

Ehinger, B., and B. Falck (1966) Concomitant adrenergic and parasympathetic fibers in the rat iris. Acta Physiol. Scand. 67: 201-207.

Eng, L. F., and S. J. DeArmond (1981) Glial fibrillary acidic (GFA) protein immunocytochemistry in development and neuropathology. In Glial and Neuronal Cell Biology, E. A. Vidio and S. Fedoroff, eds., pp. 65-79, Alan R. Liss, Inc., New York.

Eng, L. F., J. J. Vanderhaeghen, A. Bignami, and B. Gerstl (1971) An acidic protein isolated from fibrous astrocytes. Brain Res. 28: 351-354.

Falck, B. (1962) Observations on the possibilities of the cellular localization of monoamines by a fluorescence method. Acta Physiol. Scand. 56: (Suppl. 197): 1-25.

Ferri, G. -I.., I. Probert, D. Cocchia, F. Michetti, P. I. Marangos, and J. M. Polak (1982) Evidence for the presence of S100 protein in the glial component of the human enteric nervous system. Nature 297: 409-410.

Gown, A. M., and A. M. Vogel (1982) Monoclonal antibodies to intermediate filament proteins of human cells: Unique and cross-reacting antibodies. J. Cell Biol. 95: 414-424.

Haglid, K. G., A. Hamberger, H.-A. Hansson, H. Hydén, L. Persson, and L. Rönnbäck (1974) S-100 protein in synapses of the central nervous system. Nature (Lond.) 251: 532-534.

Haglid, K. G., A. Hamberger, H.-A. Hansson, H. Hydén, L. Persson, and L. Rönnbäck (1975) Cellular and subcellular distribution of the S-100 protein in rabbit and rat CNS. J. Neurosci. Res. 2: 175-191.

Hillarp, N.-A. (1946) Structure of the synapse and the peripheral innervation apparatus of the autonomic nervous system. M.D. Thesis. Acta Anat. (Basel) Suppl. 4: 1-153.

Jessen, K. R., and R. Mirsky (1980) Glial cells in the enteric nervous system contain glial fibrillary acidic protein. Nature 286: 736-737.

Lazarides, E. (1980) Intermediate filaments as mechanical integrators of cellular space. Nature 283: 249-256. 
Malmfors, T. (1965) Studies on adrenergic nerves. The use of rat and mouse iris for direct observations on their physiology and pharmacology at cellular and subcellular levels. Acta Physiol. Scand. Suppl. 248: 1-93.

Miller, A., M. Costa, J. B. Furness, and I. W. Chubb (1981) Substance $\mathrm{P}$ immunoreactive sensory nerves supply the rat iris and cornea. Neurosci. Lett. 23: 243-249.

Moore, B. W. (1965) A soluble protein characteristic of the nervous system. Biochem. Biophys. Res. Commun. 19: 739744.

Moore, B. W., and D. McGregor (1965) Chromatographic and electrophoretic fractionation of soluble proteins of brain and liver. J. Biol. Chem. 240: 1647-1653.

Olson, L., and T. Malmfors (1970) Growth characteristics of adrenergic nerves in the adult rat. Fluorescence histochemical and ${ }^{3} \mathrm{H}$-noradrenaline uptake studies using tissue transplantations to the anterior chamber of the eye. Acta Physiol. Scand. Suppl. 348: 1-112.

Pruss, R. M., R. Mirsky, M. C. Raff, R. Thorpe, A. J. Dowding, and B. H. Anderton (1981) All classes of intermediate filaments share a common antigenic determinant defined by a monoclonal antibody. Cell 27: 419-428.

Raju, T., A. Bignami, and D. Dahl (1981) In vivo and in vitro differentiation of neurons and astrocytes in the rat embryo. Immunofluorescence study with neurofilament and glial filament antisera. Dev. Biol. 85: 344-357.

Saari, M., and G. Johansson (1974) Myelinated nerves of the rat iris. Acta Anat. (Basel) 89: 139-144.

Seiger, A., D. Dahl, C. Ayer-LeLievre, and H. Björklund (1984) Appearance and distribution of neurofilament immunoreactivity in rodent iris nerves. J. Comp. Neurol., in press.

Yen, S.-H., and K. L. Fields (1981) Antibodies to neurofilament, glial filament and fibroblast intermediate filament proteins bind to different cell types of the nervous system. J. Cell Biol. 88: 115-126.

Yen, S. -H, and K. L. Fields (1983) Schwann cells contain a protein similar to the CNS astroglial filament protein. Soc. Neurosci. Abstr. 9: 235. 